\title{
Sobre política e economia: poder local e a instituição da concorrência junto aos monopólios naturais - o caso da energia elétrica nos municípios paulistas de Botucatu, Dois Córregos e Pederneiras
}

(1925-1967)

\author{
Roberval Francisco de Lima $^{1}$
}

Jefferson Costa de Souza²

\begin{abstract}
Resumo: A inserção do capital internacional na produção e comercialização de energia elétrica no Brasil em 1927, sofreu oposição de elites políticas e econômicas locais. Elaborado a partir de estudos de casos, este trabalho aborda o papel do poder local na instituição da concorrência no âmbito do fornecimento de energia elétrica em três municípios paulistas entre 1925-1967. Nosso objetivo é demonstrar empiricamente o peso e papel das instituições na conformação das regras do jogo; na delimitação do comportamento dos agentes políticos, econômicos e sociais; e delineamento de processos políticos dependentes da trajetória. Neste sentido, a análise de casos onde os processos políticos locais originaram uma antítese ao princípio econômico básico que preconiza a existência de monopólios naturais (ausência de concorrência) para assegurar a oferta dos serviços públicos, além de atender ao objetivo proposto, também estimula o debate sobre o tema no Brasil.
\end{abstract}

Palavras-chave: Poder local. Monopólios naturais. Instituição da concorrência.

\footnotetext{
${ }^{1}$ Doutorando em Ciência Política PPGPol/UFSCar. Historiador, Mestre em Ciências Sociais e Especialista em Educação Ambiental. Uma versão preliminar desse texto foi apresentada no VIII Seminário Nacional de Sociologia e Política realizado de 17 a 19 de maio de 2017 na UFPR. E-mail:limfer@uol.com.br/limfer@hotmail.com.

${ }^{2}$ Doutorando em Economia UNLAM. Bacharel em Ciências Militares, Mestre em Economia, Administrador e Contador. Oficial do Exército Brasileiro. Uma versão preliminar desse texto foi apresentada no VIII Seminário Nacional de Sociologia e Política realizado de 17 a 19 de maio de 2017 na UFPR. E-mail: capjefferson@hotmail.com.
} 


\title{
On politics and economics: local power and the institution of competition with natural monopolies - the case of electricity in the municipalities of Botucatu, Dois Córregos and Pederneiras
} (1925-1967)

\begin{abstract}
The insertion of international capital in the production and commercialization of electric power in Brazil in 1927 was opposed by local political and economic elites. Based on case studies, this paper discusses the role of local power in the institution of competition in the scope of electricity supply in three municipalities of São Paulo between 1925-1967. Our objective is to empirically demonstrate the weight and role of institutions in shaping the rules of the game; In the delimitation of the behavior of political, economic and social agents; And delineation of political processes dependent on the trajectory. In this sense, the analysis of cases where local political processes originated an antithesis to the basic economic principle that advocates the existence of natural monopolies (lack of competition) to ensure the provision of public services, in addition to meeting the proposed objective, also stimulates debate On the subject in Brazil.
\end{abstract}

Keywords: Local power. Natural monopolies. Institution of competition.

- Enviado em 01/05/2017

- Aprovado em 17/05/2017 


\section{MUNICÍPIOS PAULISTAS E ENERGIA ELÉTRICA NA PRIMEIRA METADE DO SÉCULO XX}

Para ser importante, uma história precisa ser bem contada e neste sentido, no âmbito da Ciência Política, o emprego do referencial teórico e metodológico do institucionalismo histórico pode produzir bons resultados. Elaborado a partir de análises ainda preliminares envolvendo três estudos de casos, este trabalho aborda a instituição da concorrência no âmbito do fornecimento de energia elétrica nos municípios paulistas de Botucatu, Dois Córregos e Pederneiras entre 1925 e 1967. Nos três casos estudados, a inserção do capital internacional norte americano na produção e comercialização de energia elétrica sofreu forte oposição de elites políticas e econômicas locais. Adquirida pelo grupo American \& Foreign Power-AMFORP em 1927, a Companhia Paulista de Força e Luz-CPFL teve grande participação no mercado de energia elétrica junto aos municípios do interior paulista no século passado. Criada em 1912, pelos brasileiros Manfredo Antonio da Costa e Francisco Ribeiro Moreira, a CPFL surgiu das aquisições da Empresa Força e Luz de Botucatu; Empresa Força e Luz de São Manoel; da Companhia Elétrica do Oeste de São Paulo e da Empresa Força e Luz Agudos-Pederneiras. De sua origem até a aquisição pelo grupo AMFORP, a Companhia Paulista de Força e Luz-CPFL já possuía diversas usinas hidrelétricas no Estado de São Paulo e boa parte destas já atuavam com sistemas integrados, o que lhes permitia atender as demandas das municipalidades onde possuíam contratos de concessão, dentre elas Botucatu, Dois Córregos Pederneiras. Em termos numéricos, até o momento de transferência para o capital norte americano, a CPFL detinha contratos com 22 municípios do interior paulista. A partir de 1927, já sob o capital norte americano, 18 novas hidrelétricas e seus respectivos contratos de concessão com municípios foram incorporados à $\mathrm{CPFL}$, passando esta a atender um total de 40 municípios no Estado de São Paulo em 1930 (CPFL/MEMÓRIA). O objetivo do nosso artigo é demonstrar empiricamente o peso e papel das instituições formais na conformação das regras do jogo; na delimitação do comportamento dos agentes políticos, econômicos e sociais; e no delineamento de processos políticos dependentes da trajetória. A seleção dos casos onde os processos políticos deram origem a instituição de uma antítese ao princípio econômico básico (monopólios naturais) que preconiza a ausência de concorrência para assegurar a oferta dos serviços públicos, além de atender ao objetivo proposto, também estimula o debate e produção 
de novos estudos sobre o tema no Brasil. Em linhas gerais, dos 245 municípios paulistas existentes até a década de 1930, 110 deles possuíam fornecimento de energia elétrica gerado por hidrelétricas, ${ }^{3}$ que eram constituídas por grupos de empresários brasileiros com escopo de atuação local e regional (MORTARI; FERRÃO, 2014). Neste cenário de popularização do acesso a energia elétrica, nos municípios de Botucatu (1907); Dois Córregos (1910) e Pederneiras (1910) não fogem a regra, e nas datas citadas entre parênteses, ocorrem as inaugurações dos serviços de iluminação pública nas cidades analisadas. Até a inserção do capital internacional na produção de energia elétrica no Brasil que ocorreu na década de 20 do século passado, para atender a crescente demanda por energia elétrica, os empreendedores nacionais organizaram-se em pequenos conglomerados regionais. Em termos gerais, os contratos para oferta de energia elétrica eram feitos diretamente entre prefeitura e fornecedor, e a exclusividade na prestação do serviço, era a regra contratual que assegurava ao contratado, a lucratividade do negócio que só ocorreria após vários anos de exploração da atividade. Em outras palavras, o impedimento legal à entrada de novos agentes econômicos no mercado local de energia (monopólio natural), era a condição sine qua non para que os contratos de fornecimento de eletricidade pudessem ser estabelecidos. Implícito a este contexto e emprestando maior relevância aos casos estudados, cabe perguntar: porque Botucatu; Dois Córregos e Pederneiras institucionalizaram mantiveram por décadas a concorrência numa área da atividade econômica tradicionalmente reconhecida como de monopólio natural? Acreditamos que se o institucionalismo histórico não responder este questionamento, ao menos nos indicará as melhores hipóteses para sua resolução.

\section{O INSTITUCIONALISMO HISTÓRICO}

O Institucionalismo Histórico considera o poder como marco central da vida política. Neste sentido, os conflitos oriundos das disputas políticas entre grupos rivais pela apropriação de poder e de recursos, torna-se o elemento fundamental dos processos políticos (HAAL; TAYLOR, 2003);

\footnotetext{
${ }^{3}$ Também existiam municípios cuja energia elétrica provinha de hidrelétricas instaladas em outros estados e alguns municípios também eram atendidos por termoelétricas.
} 
(ROTHSTEIN, 2001). Para os institucionalistas históricos, os Estados não são agentes neutros da história, ao contrário, os Estados são permeados pelas assimetrias de poder que influenciam diretamente na forma como os Estados por meio de suas instituições, estruturam a distribuição do poder; condicionam as ações estratégicas que os diferentes grupos podem utilizar para acessar este recurso; e até mesmo, a forma como esses diferentes grupos sociais definem seus interesses políticos. Nessa perspectiva, o Estado influencia diretamente nos resultados dos conflitos (ROTHSTEIN 2001:213-214) e (HALL; TAYLOR, 2003:193-195). Mesmo considerando válida a concepção de comunidade política como um sistema complexo formado por partes que interagem, esta corrente de pensamento não atribui papel preponderante aos aspectos culturais, sociais e psicológicos dos indivíduos como sendo elementos responsáveis pelo funcionamento do sistema político. Segundo os institucionalistas históricos, é a organização institucional da comunidade política que estrutura o comportamento coletivo (ROTHSTEIN 2001:211); (HALL; TAYLOR, 2003:194-195). Aos institucionalistas históricos, importa como as instituições políticas oficiais influenciam na distribuição de poder e recursos, e os conflitos daí originados, sejam eles entre grupos políticos ou mesmo entre a própria organização institucional da comunidade política e as estruturas econômicas de mercado (HALL; TAYLOR, 2003: 195; 199-200). Nas palavras dos autores, contrariando o princípio da plena liberdade individual na elaboração de contratos, os institucionalistas históricos:

(...) preferem postular um mundo onde as instituições conferem a certos grupos ou interesses um acesso desproporcional ao processo de decisão. Além disso, ao invés de investigar em que medida uma situação dada beneficia a todos, eles tendem a insistir no fato de que certos grupos sociais revelam-se perdedores, enquanto outros são ganhadores. (HALL; TAYLOR, 2003: 200)

Embora o evidente determinismo cause desconforto, o avanço das pesquisas orientadas por esse viés (institucionalista histórico) deu-se principalmente por meio da realização de estudos na área da política comparada envolvendo diferentes países. Metodologicamente, o caráter predominante nesses trabalhos era a distribuição dos eventos e processos políticos em análise, ao longo de amplos horizontes temporais. Como exemplo dos significativos resultados alcançados por essa abordagem (e fortalecendo o desconforto), sob enfoque mais econômico, podemos citar os resultados apontados por North (2003), que ao comparar as diferenças entre o desenvolvimento 
econômico alcançado pela Espanha e Inglaterra, destaca a centralidade do papel das instituições que esses países criaram para superarem uma crise que lhes foi comum no século XVI. Em síntese, países e contexto socioeconômico semelhante (feudais); a partir da adoção de instituições distintas (estruturação da burocracia x estruturação do sistema financeiro), conquistaram resultados diferentes ao longo da história. Já na perspectiva da ciência política, Rothstein (2001:211) cita o trabalho de Steino (1993) que ao comparar os EUA, o Reino Unido e a Suécia, demonstrou que naqueles países foi preponderante o papel das constituições (regras formais) na distribuição das obrigações fiscais, e não a força organizativa das diferentes classes sociais. Nesta perspectiva, e colaborando com os institucionalistas históricos, os exemplos tornam claro o peso e o papel das instituições na organização da vida social. Como veremos adiante, os trabalhos de Pierson (2000 e 2004) são esclarecedores com relação aos princípios teóricos e métodos inerentes à valoração dos processos históricos (tempo e sequencia) quando das análises da Ciência Política para atingir resultados semelhantes aos exemplos citados. No momento, é desejável destacar que na perspectiva dos institucionalistas históricos, as instituições são vistas de uma maneira ampla e distante dos embates entre a influência cultural e racional em sua composição. Ao incorporarem elementos das políticas públicas, os institucionalistas históricos focam nos processos decisórios no âmbito do Estado, e as regras daí estabelecidas, que gozam de legitimidade (e poder de coerção) entre os atores, portanto passam a regular as condutas de indivíduos, grupos e organizações. Disso resulta uma concepção de instituição como um conjunto de normas oficiais definidoras de procedimentos e modelos de funcionamento. Essas normas políticas que nas palavras de Hall; Taylor (2003: 200) "repartem o poder de maneira desigual entre os grupos sociais", paradoxalmente envolvem o estabelecimento de acordos tácitos e explícitos, devidamente reconhecidos e acatados pelos atores, cuja ação passa ser condicionada a partir das normas instituídas (ROTHSTEIN, 2001); (HALL; TAYLOR, 2003). A partir desta noção ampla de instituição (embora imprecisa), central ao institucionalismo histórico é o vínculo com o modelo explicativo do desenvolvimento histórico enquanto dependente da trajetória, onde a partir de uma instituição (normais oficiais), delimita-se um trajeto a ser percorrido, e a cada passo dado pelos atores seguindo nesta trajetória, torna-se mais difícil sair da rota estabelecida (HALL; TAYLOR, 2003); (ROTHSTEIN; 2001); (PIERSON; 2004 e 2000). No entanto, valendo se de ferramentas analíticas próprias do ambiente econômico, Pierson (2004) destaca que a manutenção da dependência da trajetória só é viável se ela permitir aos atores e processos políticos, retornos crescentes ou como 
é mais conhecido no âmbito da ciência política, feedbacks positivos. Para o autor, a ausência de retornos crescentes diminuiriam os custos políticos envolvidos na mudança de trajetória e abriria espaço para ocorrência de momentos críticos onde a mudança institucional seria possível (PIERSON, 2004). Nesta mesma linha de raciocínio Rothstein (2001), destaca que as mudanças institucionais podem decorrer de fatores endógenos ou exógenos. Quando endógenas, estas dizem respeito a pequenas mudanças ou realinhamento das ações que embora de modo incremental, podem ocasionar grandes transformações nos resultados dos processos políticos ${ }^{4}$. Já as mudanças de caráter exógenos, podem decorrer daquilo que convencionou-se chamar de acidentes de percursos (guerras, catástrofes). No geral, em situações onde os atores possuem capacidade para mudar as regras do jogo, seja por fatores endógenos ou exógenos, temos aquilo que ficou conhecido pela literatura da ciência política como conjunturas críticas ou momentos formativos, que nas palavras de ROTHSTEIN (2001:236), são os momentos em que os atores políticos possuem capacidades para mudar as regras do jogo, principalmente porque as instituições políticas existentes são incapazes de oferecem respostas razoáveis a novos desafios ou contextos. Tratando das mudanças institucionais, Hall; Taylor (2003) concorda que as conjunturas críticas ou momentos formativos são mesmo permeados pela possibilidade de mudanças institucionais, mas destacam a baixa eficiência do institucionalismo histórico no estabelecimento de modelos explicativos sobre as mudanças institucionais, sendo as crises econômicas e conflitos militares os exemplos mais corriqueiros utilizados por autores desta corrente. Em outras palavras, as assimetrias de poder endógenas às instituições e tão caras aos institucionalistas históricos, reforçam o caráter menos dinâmico das mudanças institucionais, que inclusive tendem a reforçar a manutenção da dependência da trajetória, imputando restrições aos atores caso desviem da rota. Em contraponto, ao tratar da aplicabilidade do conceito de retornos crescentes às análises próprias da ciência política, Pierson $(2004 ; 2000)$ destaca a necessidade de se alongar os horizontes das análises, e considerar hipóteses baseadas na ordem temporal dos processos históricos. Nesta perspectiva, o autor sugere que muito da estabilidade encontrada nas instituições políticas e reforçadas pela dependência da trajetória, na verdade se originam daquilo que é uma das características centrais da política: produzir bens públicos, inclusive e por meio de

\footnotetext{
${ }^{4}$ Para uma abordagem mais elaborada sobre processos de institucionalização e mudanças institucionais ver BLONDEL (2008) e MAHONEY; THELEN (2010).
} 
políticas públicas ${ }^{5}$. Caracterizados pelo elevado custo de instalação, indivisibilidade da oferta e a não exclusão dos cidadãos do acesso ao bem, a provisão de bens públicos requer dos sistemas políticos, a criação de uma rede complexa de instituições complementares ao Estado, que a partir de um conjunto de regras compulsórias, façam valer os princípios legais e normativos estabelecidos. Em suma, nesta linha de raciocínio a manutenção da oferta dos bens públicos ao longo de grandes períodos, requer a manutenção das normas estabelecidas, disso resulta uma dependência de trajetória, inclusive porque em relação aos bens públicos, mudanças na trajetória estabelecida em sua oferta, podem implicar em novos e elevados custos de instalação (econômicos e políticos), que se não forem contemplados quando da opção pela mudança, podem levar à exclusividade na oferta (parte da população ficaria sem acesso ao bem), contrariando assim, o princípio da universalidade das políticas públicas no fornecimento de bens públicos. Apesar de não ficar tão evidente em seus argumentos, implícito ao raciocínio de Pierson (2004; 2000) é a ideia que os retornos crescentes nos processos políticos ligados a provisão de bens públicos, produzem ganhos coletivos (acesso ao bem), e não somente ganhos para os atores políticos (assimetria ou equilíbrio de poder, autoridade para definir regras, possibilidades de reeleição). Por outro lado, o próprio autor destaca que a manutenção de feedbacks positivos por longos períodos, reforçam muito as assimetrias de poder; a ponto de tornarem-se pouco perceptíveis aos que estão em desvantagem no acesso a este recurso. Na prática, a manutenção deste processo de feedback positivo ampliaria as assimetrias de poder a ponto dos atores fortalecidos poderem valer-se da autoridade política para impor-se aos demais, criando assim situações de autorreforço de poder com boa margem para possibilidade de mudanças institucionais e mesmo mudanças nas políticas públicas (PIERSON, 2004; 2000). Numa tentativa de síntese, na perspectiva de Pierson (2004; 2000), dada prevalência das assimetrias de poder, a mudança institucional também pode ocorrer a partir de grupos que foram fortalecidos no âmbito da dependência da trajetória e acesso desigual a seus retornos crescentes (feedback positivos) por longos períodos, condição que além de reforçar e ampliar ainda mais as assimetrias de poder pode torna-los preponderantes aos demais, e capazes de gerarem mudanças institucionais.

\footnotetext{
${ }^{5}$ Segurança Nacional e defesa do meio ambiente são exemplos de bens públicos puros, não passíveis de serem ofertados pelo mercado. Serviços de iluminação pública; distribuição de energia elétrica e serviços de saneamento básico são exemplos de serviços de serviços públicos de infraestrutura que podem ser ofertados pelo mercado, sob regulação de instituições públicas.
} 


\section{SERVIÇOS DE INFRAESTRUTURAS E MONOPÓLIOS NATURAIS}

$\mathrm{Na}$ atualidade, as especificidades do fornecimento de energia elétrica inserem se no âmbito dos serviços públicos de infraestrutura. Como sua oferta destina-se a satisfação das necessidades coletivas, mesmo sendo ofertado pelo setor privado, esses serviços ainda mantém o princípio da universalidade e da não exclusão de cidadãos do acesso ao bem. No Brasil, prevalece à organização institucional da oferta dos serviços públicos de infraestrutura em regimes de monopólios naturais (não permite a existência de mais de um fornecedor no mesmo território), e no caso da energia elétrica, a regulamentação do setor criou duas características de consumidores, a saber, consumidores cativos que não podem escolher de quem comprar energia elétrica e consumidores livres, que por meio de leilões, podem selecionar de quem e a que preço comprar sua energia. Os primeiros são compostos por pequenos consumidores e consumidores residenciais, já os segundos, são formados basicamente por grandes consumidores, que para receberem a energia comprada, pagam uma taxa pelo uso da rede de distribuição. Adiante veremos como os três municípios estudados equacionaram a seu modo e no seu tempo, os desafios ligados ao fornecimento de energia elétrica no período de 1925-1967.

\section{DOI CÓRREGOS - SP}

A primeira história aqui contada é da Companhia Independência de Eletricidade, constituída em Jau-SP, na década de 1928 e que ao longo de seus 33 anos de existência, foi concorrente da CPFL, principalmente no município de Dois Córregos -SP. Apesar de sediada em Jaú, a unidade geradora da Cia Independência foi estrategicamente instalada numa localização privilegiada entre os municípios de Jau e Dois Córregos, que distam aproximadamente $30 \mathrm{~km}$ um do outro. Embora o Diário Oficial do Estado de São Paulo, edição de 18/12/1929 mencione que a referida Cia detinha desde 1928, a autorização para exploração do comércio de energia elétrica no 
município de Jáu, nos levantamentos realizados, não identificamos documentos referentes a efetiva concorrência da Cia Independência com CPFL na área urbana deste município. No entanto, considerando as informações presentes no site da própria CPFL; nos registros da do Diário Oficial do Estado de São Paulo e da atual localização das ruínas da Usina Hidrelétrica Independência, nota-se que provavelmente a Cia Independência comercializava sua energia nos bairros rurais situados em áreas dos dois municípios, com destaque para o atual distrito de Guarapuã, hoje pertencente a Dois Córregos. Voltando ao que importa, a sutileza do nome Cia Independência nos faz lembrar que após 1927, a CPFL bem como suas concessões no interior do Estado de São Paulo fora adquirida pelo grupo norte americano AMFORP. Se em Jaú a concorrência entre CPFL e Cia Independência não ocorrera de fato, em Dois Córregos houve uma situação diferenciada, pois em 1929 há a transferência dos serviços de iluminação pública antes ofertados pela CPFL, para a Cia Independência de Eletricidade, cuja oferta de iluminação pública na cidade perdurou até 1961, ano em que a estrutura da Cia independência foi transferida para a municipalidade e posteriormente a uma autarquia do governo federal, no caso a Eletrobrás. No caso de Dois Córregos, a localização e análise de documentos que tratam da concorrência no referido período está em processo, mas em termos políticos e estratégicos cabe considerar que originalmente entre os fundadores da Cia Independência de Eletricidade constam membros de gerações distintas da mesma família. Idealizada por José Toledo de Moraes, na época engenheiro e político local que foi prefeito de Jaú no mandato de 1924-1929, estando a frente desta prefeitura, foi o responsável em 1928 pela concessão da autorização para que a Cia Independência de Eletricidade pudesse explorar os serviços de comercialização de energia elétrica no referido município. Estrategicamente, a Usina Hidrelétrica Independência fora criada por Carlota Victoria de Moraes, avó materna do referido prefeito (CPFL/MEMÓRIA), em terras da fazenda da respectiva família, que inclusive adquiriu áreas anexas para efetivação do empreendimento hidrelétrico. Com o fim de seu mandato, o engenheiro assume a liderança no empreendimento hidrelétrico constituído no âmbito de sua família, e como legalmente possuía autorizações para comercialização de energia elétrica em municípios distintos e vizinhos (Jaú e Dois Córregos), provavelmente optou por centralizar esforços naquele onde sua capacidade produtiva lhe permitiria assumir a liderança na iluminação pública, no caso Dois Córregos, de porte menor que Jaú e onde possuíam grandes propriedades rurais. Em ambiente de baixa industrialização, 0 fornecimento de energia elétrica para iluminação pública era o segmento mais rentável para os 
empreendedores hidrelétricos da época, fato que lhes podia render tanto o retorno econômico da atividade quanto a expansão de seu capital político.

\section{PEDERNEIRAS - SP}

Com similaridade e amplas diferenças, nossa segunda história trata da concorrência entre a Empresa Força e Luz de Pederneiras Ltda e a CPFL, esta última, responsável desde 1910 pelo fornecimento de energia elétrica no município de Pederneiras -SP. Criada em 1927 por um grupo formado por 13 empresários locais que entre 1920 a 1970, revezaram- se a frente da prefeitura municipal por 09, dos 17 mandatos do período, a produção da Empresa de Força e Luz de Pederneiras cuja planta física localizava-se no Rio Bauru, próximo a sua foz no Rio Tietê, servia tanto para atender a demanda por energia elétrica de seus acionistas, como para comercializar a energia junto ao município, em concorrência com a CPFL. Segundo jornais da época, tanto em Botucatu como em Pederneiras, CPFL era chamada pelos populares de Companhia Pisca Pisca, dado as falhas no fornecimento de energia. Além da produção agropecuária, nas fazendas destes empreendedores- políticos também existiam estruturas e maquinários para o beneficiamento da respectiva produção, cerâmicas e olarias para produção de telhas, tijolos que demandavam o uso crescente da energia. Alguns deles também eram proprietários das casas de comércio na área urbana do município, fatos que em tese justificam o investimento para produção de energia elétrica, no entanto, é sabido que a lucratividade do empreendimento seria melhor assegurada se pudessem comercializar a energia excedente junto ao poder público municipal e demais consumidores urbanos. Neste contexto, na gestão de Serafim Ferreira dos Santos (1929-1930), a empresa de Força e Luz de Pederneiras assina o contrato com a Câmara Municipal do Município para fornecer energia elétrica na área urbana da cidade, bem como para a iluminação pública local. A partir de então e inusitadamente, em Pederneiras-SP, de 1929 a 1967, em muitas ruas da cidade, duas redes de energia elétrica pertencentes às empresas concorrentes disputavam espaços e consumidores de energia. Sobre a efetividade dessa concorrência, merece destaque uma matéria publicada no Jornal Correio Paulistano, edição de 17 de maio de 1936, onde destaca- 
se a concorrência desleal praticada pela CPFL, que para competir com a Empresa Força e Luz de Pederneiras e atrair um número maior de consumidores, praticava tarifas menores que as de seu concorrente. Assim, no fornecimento de energia para iluminação pública como para fins particulares, as duas empresas em questão competiram por seus consumidores até 1967, quando a Empresa Força e Luz de Pederneiras foi encampada pelo governo federal e doada ao governo do Estado de São Paulo. Entre outros, o motivo para encampação deu-se pela incapacidade da Força e Luz de Pederneiras em expandir suas atividades. Ao fim do processo de encampação, a rede de distribuição da Empresa foi incorporado ao patrimônio municipal e posteriormente doado à CPFL, posteriormente incorporada pela ELETROBRAS. Seu maquinário foi retirado e sua planta física foi inundada pelo enchimento do lago formado pela da barragem da Usina Hidrelétrica Álvaro de Souza Lima (1967), situada no Rio Tietê, distante cerca de $05 \mathrm{~km}$ e a jusante da foz do Rio Bauru. Curiosamente, boa parte do território alagado por este último empreendimento efetivado pelo governo do estado, pertencia justamente a áreas das fazendas de 03 acionistas da Empresa Força e Luz de Pederneiras. A CPFL que ficara fortalecida neste processo, posteriormente também teve seus ativos locais incorporados pelo governo federal via Eletrobrás. Importa destacar que durante o período que vigorou a concorrência entre as duas empresas, alguns distritos e áreas rurais do município não eram atendidas com energia elétrica, o que gerou novas autorizações por parte da prefeitura para que empresas de menor porte se instalassem para atender os referidos distritos. $\mathrm{A}$ legislação da época também nos mostra que eram comuns os atrasos nos pagamentos anuais aos fornecedores de energia, um possível indício do jogo de forças locais que revezavam se no poder, ora favorecendo a empresa local, ora favorecendo a CPFL, no entanto, ambas sofriam com os atrasos nos pagamentos.

\section{BOTUCATU - SP}

No caso de Botucatu, a concorrência para fornecimento de energia elétrica começa antes mesma da entrada dos norte americanos no mercado energético local. Institucionalizada em 1925, a concorrência entre a Companhia Paulista de Força e Luz-CPFL e a Uzina Hydro Elétrica Bacchi 
(grafia da época) para o fornecimento de energia elétrica ao município se dá num contexto de disputas pelo poder entre dois grupos políticos rivais, a saber, cardosistas e amandistas, âmbos compostos por lideranças dos setores comerciais e industriais. Aos primeiros, coube a inauguração da energia elétrica no município e a criação da própria CPFL, depois vendida aos norte americanos. Aos segundos, coube a pressão pela inserção da concorrência no âmbito do fornecimento de energia elétrica, dado que Petrarca Bacchi, um importante empresário local proprietário da Uzina Hydro Elétrica Bacchi, que com apoio dos amandistas, conquistou direito de comercializar a energia excedente de sua usina no município. Uma vez instituída a concorrência pelo poder público local, nos anos que seguem (1925-1948), talvez primeiramente preocupadas em recuperar os custos de instalação, as duas empresas vão distribuindo pelas ruas da cidade, os cabos e fios de suas respectivas redes de distribuição de eletricidade, e passam a competir pelos consumidores particulares de energia, sejam eles comerciais, residenciais ou industriais, dado que o setor público, mesmo sob questionamentos da população, mantém o contrato com a CPFL para iluminação pública (PUPPO, 2002: 169-170). Com maior capacidade produtiva e menos sujeito a queda no fornecimento, para competir Bacchi opta por usar a estratégia de tarifas com preços fixos e menores que os da CPFL para todos os tipos de consumidores, conquistando assim muitos clientes residenciais, comerciais e principalmente industriais. Como a concorrência implicou em queda no faturamento da CPFL, obviamente a questão foi judicializada e mesmo tento a CPFL recorrido ao Supremo Tribunal Federal, em todas as instancias, a justiça dá ganho de causa a Bacchi, assegurando-Ihe o direito de comercializar sua energia no município BRASIL (1932). Diante do insucesso no embate jurídico que durou anos, a CPFL, mudou sua estratégia de posicionamento no mercado. Seus valores tarifários eram padronizados e tinham os mesmos valores em todos os municípios que atendia (sem concorrência), e eram superiores aos praticados por Bacchi (PUPO, 2002). Como estratégia, além do uso de medidores mais precisos para aferição do consumo real dos consumidores, visando uma possível queda nos valores cobrados, esta também inaugurou em Botucatu, uma grande loja de eletrodomésticos, que na época, representavam a novidade do momento e eram símbolos de modernidade para a população (BOTARO, 2015; 2014). Estrategicamente, além de fazer uma ampla divulgação dos aparelhos, a CPFL fornecia descontos aos compradores de eletrodomésticos que fossem usuários da sua energia elétrica (BOTARO, 2014: 129-132). Neste cenário, cabia à população em geral, a liberdade de escolha em relação de quem comprar energia, se da CPFL, ou se de Bacchi. Preferências individuais ou situacionais à 
parte, segundo Pupo (2002: 237; 240; 252) em termos comparativos, no geral as duas empresas apresentavam desafios com relação a qualidade dos serviços ofertados. Na balança da qualidade, Bacchi era beneficiado. Embora menos frequente, as interrupções no fornecimento de sua energia eram mais duradouros, no entanto, fontes secundárias consultadas apontam um volume maior de reclamações da intermitência no fornecimento de energia por parte da CPFL. A manutenção de Bacchi como uma opção viável para fornecimento de energia elétrica à iluminação pública; bem como o seu efetivo fornecimento de energia aos consumidores sob preços menores que os da CPFL, possivelmente potencializava o prestígio do grupo político local (amandistas). Reportagens dá época mostram que Bacchi tinha pretensão de atender bairros e distritos distantes do centro da cidade com iluminação pública, para isso só precisava ser contratado pela prefeitura (PUPO, 2002). Os jornais da época também faziam comparações entre os preços da energia de Bacchi e da CPFL e questionavam porque não se contratava Bacchi para iluminar as ruas da cidade, dado que segundo os jornais, sua energia era melhor e mais barata. Quando questionados, dirigentes políticos da oposição (cardosistas) reiteravam a necessidade da manutenção das regras contratuais, referindo-se a necessidade de respeitar o contrato estabelecido com a CPFL, agora sob propriedade dos norte americanos (PUPO, 2002). Embora contraditória, essa situação perdurou de 1925 até 1948, quando após a morte de Bacchi em 1940, seus filhos optaram por desfazerem-se da Uzina Bacchi em 1948.

\section{MUNICÍPIOS E CONCORRÊNCIA ENTRE MONOPÓLIOS NATURIAS: ALGUMAS CONSIDERAÇÕES}

Como foi possível verificar, nos três casos estudados, o principal elemento comum que os integram no âmbito da instituição da concorrência para o fornecimento de energia elétrica na esfera municipal, é a trajetória criada com o consumo de energia elétrica que popularizou-se nos municípios do interior paulista no começo do século passado. A demanda crescente pelo uso de energia junto aos municípios obrigava o poder público local a criarem estratégias para expandirem a oferta deste insumo básico para o desenvolvimento das atividades econômicas e sociais. Foi neste cenário que a CPFL ainda sob propriedade nacional, conseguiu expandir sua área de 
atuação. Paralelo aos grupos locais que disputavam poder entre si, a inserção do capital norte americano no fornecimento de energia elétrica ao interior paulista ocorrido em 1927, ao menos nos municípios estudados parece ter representado uma oportunidade para as elites locais, que conseguiram se inserir no mercado de fornecimento de energia elétrica justamente no momento de transição da CPFL para o capital internacional. Nos três casos, a instituição da concorrência, ou seja, a entrada de atores locais para competirem com AMFORP/CPFL no fornecimento de energia elétrica aos seus municípios, se dá entre 1925-1928, ou seja, no período de transição da CPFL para o capital internacional. Por outro lado, o momento crítico para que esta inserção dos atores locais na produção de energia desse certo, parece ter sido a incapacidade da CPFL em atender a demanda por energia elétrica junto às municipalidades. Uma vez instituída a concorrência como norma, não foi possível muda-la e nos casos estudados ela se manteve ao longo de décadas, a saber, 23 anos em Botucatu; 38 anos em Pederneiras e 36 anos em Dois Córregos, condicionando os atores econômicos a competirem entre si. Mesmo em Dois Córregos, localidade onde dispomos de restritas fontes de informações, a CPFL não deixou de participar do mercado local. Por outro lado, nos três casos estudados foram fatores exógenos ao poder local que levaram ao fim da concorrência. Em Botucatu, a morte do fundador da Uzina Bacchi levou os filhos a venderem a empresas em anos subsequentes. Em Pederneiras, a encampação da Empresa Força e Luz de Pederneiras pelo governo federal quando da construção da Usina Hidrelétrica Alvaro de Souza Lima, também não está diretamente relacionado ao jogo político local. Semelhante a Pederneiras, em Dois Córregos, a Companhia Independência de Eletricidade é incorporada ao patrimônio municipal em momentos que antecedem a encampação das pequenas unidades produtores de energia elétrica, (inclusive a CPFL em Dois Córregos), por parte do governo federal quando da formação da Eletrobrás, uma holding de capital misto criada pelo governo federal na época e que até hoje atua no setor elétrico brasileiro. Em outras palavras, coube a fatores exógenos à mudança na trajetória estabelecida pelas elites políticas e econômicas dos municípios estudados que inovaram ao institucionalizarem a concorrência no âmbito do fornecimento de energia elétrica em seus territórios. Ainda que provisoriamente, pois o tema e os casos merecem estudos mais aprofundados, mas tentado responder a pergunta inicial do trabalho, os resultados da análise apontam que nos municípios de Botucatu, Pederneiras e Dois Córregos, a instituição da concorrência se deu por duplo objetivo. Além de superar o momento crítico originado por uma instituição anterior que legitimava o monopólio e comprometia a oferta de um bem público, a 
nosso ver ela também significou uma correção nas assimetrias de poder entre os grupos políticos e dirigentes locais, que aparentemente não competiam no setor, quando a CPFL ainda estava sob comando do capital nacional. O poder da instituição concorrência sobre o comportamento dos atores fica evidente quando os políticos alteram as regras contratuais que previam monopólio natural e instituem a concorrência com fins de manterem-se na trajetória estabelecida, no caso atender a crescente demanda por energia elétrica. Uma vez instituída, mesmo diante das assimetrias de poder, que em Pederneiras ficam evidentes com os sucessivos atrasos de pagamentos por parte da prefeitura, e em Botucatu com a não contratação de Bacchi para iluminação pública, os atores políticos mantiveram-se num equilíbrio de poder e a concorrência não foi revista. Sua extinção se dá por fatores exógenos. A partir da instituição da concorrência, os atores econômicos passam literalmente a competir entre si, numa situação inusitada de antítese ao princípio de monopólio natural. Por fim, navegando de um fornecedor para outro e questionando a qualidade dos serviços ofertados, a população aparentemente acomodou-se diante das duas opções que tinham disponíveis. Afinal, no que se refere aos serviços de fornecimento de energia elétrica no interior do Estado de São Paulo, até onde se sabe, os municípios de Botucatu, Pederneiras e Dois Córregos foram pioneiros ao ofertarem aos seus moradores, a liberdade de escolha.

\section{REFERÊNCIAS}

A GAZETA DE BOTUCATU. Edição Especial Comemorativa de Aniversário de Botucatu. Segundo Caderno Especial 151 anos. Botucatu, Cidade das Boas Industriais. A Gazeta de Botucatu, Botucatu, Sexta Feira, 14 abril 2006. Edição Especial.

Suplemento Especial. Botucatu. Crônica dos Presidentes da

Câmara Municipal (1855- 2007). A Gazeta de Botucatu, Botucatu, Sexta Feira, 13 abril 2007. Edição Especial. 
BRASIL. Diário Oficial da União. Edição de 29 de abril de 1913. Companhia Paulista de Força e LuzCPFL. Manifesto para Emissão de Um Empréstimo. Páginas: 72-74. Disponível em: www.jusbrasil.com.br/diários. Edição de 08 de Setembro de 1932. Despacho do Chefe do Governo Provisório da República. Processo №2 A 31, Município №35-Botucatu. Exclusividade CPFL x BACCHI. Página 02. Disponível em: $\underline{w w w . j u s b r a s i l . c o m . b r / d i a ́ r i o s . ~}$

. Seção 1 - 17/1/1967, Página 674. DECRETO № 60.054, DE 12 DE JANEIRO DE 1967. Autoriza o Govêrno do Estado de São Paulo a encampar os bens e instalações vinculadas aos serviços de energia elétrica no Município de Pederneiras, Estado de São Paulo. Disponível em: www.jusbrasil.com.br/diários.

BOTUCATU. Prefeitura Municipal de Botucatu-PMB. Lei №63, de 03 de dezembro de 1948. Autoriza Prefeitura Municipal de Botucatu a receber em doação, terras e a Uzina Hidro Elétrica Bacchi, e doação para a Companhia Paulista de Força e Luz-CPFL. Botucatu, 1948.

BLONDEL, Jean. ABOUT INSTITUTIONS, MAINLY, BUT NOT EXCLUSIVELY, POLITICAL. In: BINDER, S. A; RHODES, A. W; ROCKMAN, B. A. (eds.). The Oxford Handbook of Political Institutions. Oxford: Oxford University Press, 2008. p. 716-730.

BOTARO, Luiz G. M. Cidade de Botucatu, Símbolos e Experiências da Modernidade entre os anos de 1928-1934. Revista Semina, Passou Fundo, v.13, n0⒈ p.227-251, 2014.

Botucatu: modernização e infraestrutura urbana no interior paulista (19281934). 2015. Dissertação (Mestrado em História) Universidade Estadual Paulista-UNESP, Assis.

COMPANHIA PAULISTA DE FORÇA E LUZ-CPFL. Projeto memória viva. Disponível em: www.cpfl.com.br/institucional/quemsomos/memoriaviva.

HALL, P; TAYLOR, R. As três versões do neo-institucionalismo. Lua Nova-Revista de Cultura e Política. São Paulo, n.58, p. 193-223, 2003.

MAHONEY, J; THELEN, K. A Theory of Gradual Institutional Change. In: . (eds.). Explaining Institutional Change: Ambiguity, Agency, and Power. Cambridge: Cambridge University Press, 2010.p.1-37. 
MORTARI, D. M. A.N; FERRÃO, A.M.A. O papel das primeiras usinas hidrelétricas na urbanização do Estado de São Paulo. Revista de Gestão de Águas da América Latina, Porto Alegre, v.11, n1, p75-88, jan/jul, 2014.

NORTH, Douglass. Instituciones, Cambio Institucional y desempeno econômico. México, Fondo de Cultura Econômica, 1993.

PREFEITURA MUNICIPAL DE PEDERNEIRAS-PMP. Lei № 98 de 02 de setembro de 1929. Autorização a Prefeitura Municipal de Pederneiras a contratar a Empresa de Força e Luz de Pederneiras para oferta dos serviços de iluminação pública...Pederneiras, 1929.

Lei № 18 de 05 de outubro de 1966.

Autoriza a Prefeitura a contratar os senhores José Vieira Motta e Miguel Grecco para fornecimento de iluminação pública do Distrito de Vanglória. Pederneiras, 1936.

- Lei № 60 de 01 de julho de 1927.

Autoriza a Prefeitura a pagar para CPFL, os valores em atraso referente ao fornecimento de energia elétrica e força a esta cidade. Pederneiras, 1927.

. Lei № 731 de 28/12/1963. Dispõe sobre

o pagamento de Dívida à Empresa Força e Luz de Pederneiras- Ltda. Pederneiras, 1963.

. Lei № 90 de 22 de junho de 1949. Sobre

iluminação da Avenida Antonio Ruiz Romero, concedida a Empresa Força e Luz de Pederneiras Ltda. Pederneiras, 1949.

Lei № 365 de julho de 1955. Autoriza o

pagamento à Empresa Força e Luz de Pederneiras Ltda pelos serviços de iluminação pública. Pederneiras, 1955.

PIERSON, P. Increasing returns, path dependence, and the study of Politics. The American Political Science Review, Cambridge. v. 94, n. 2, p. 251-267, jun. 2000.

PIERSON, P. Politics in time: History, institutions and social analysis. Princeton University Press, Princeton, 2004. 
PUPO, Trajano Carlos F. Botucatu de Antigamente. De 1919 até 1948. Vol.Il. Otoni Editora. Botucatu, 2002.

PUPO, Trajano Carlos F. Botucatu de Antigamente. Das origens até 1917. Vol.I. Otoni Editora. Botucatu, 2002.

ROTH, G. The Private Provision of The Public Service in Developing Countries. World bank, Oxford, 1987.

ROTHSTEIN, B. Las instituciones políticas: una visión general. In: R. GOODIN, R; KLINGEMAN, H. D. (eds.) Nuevo Manual de Ciencia Política. Madrid: Istmo,2001.p. 199-246. 